Arteterapia. Papeles de arteterapia y educación para inclusión social ISSN: $1886-6190$

\title{
Arteterapia y musicoterapia en la etapa prenatal, paternidad, maternidad y post-parto. Recursos creativos para profesionales que les acompañan
}

\author{
Anna Freijomil Reverter ${ }^{1}$
}

Recibido: 20 de junio de 2016 / Aceptado: 3 de julio de 2016

Resumen. El arteterapia aplicada a la etapa prenatal es una aplicación poco conocida en nuestro país que aborda psicoemocionalmente, el periodo de gestación de la madre. Fortalece los vínculos entre la madre, el bebé prenatal y el padre. Acompañamiento post-parto a la pareja. También pretende llegar a ser un recurso creativo para profesionales de la salud que acompañan a mujeres en su maternidad.

Palabras clave: Embarazo; vínculo; maternidad; arteterapia; empoderamiento.

\section{[en] Art therapy and music therapy in the prenatal period, paternity,} maternity and postpartum. resources for creative professionals accompany them

Abstract. Art-therapy applied to the prenatal stage is an innovative application in our country that deals with psycho-emotional during the gestation period of the mother. It strengthens the links between the mother, baby and father prenatal, postpartum, accompanying the couple. It also aims to become a creative resource for health professionals who accompany women in their childbearing.

Keywords: Pregnancy; attachment; maternity; art therapy; empowerment.

Sumario. 1. Introducción, el encuadre autoetnográfico: una forma narrativa de generación de conocimientos; 2. Arteterapia Interdisciplinar; 3. Como empezó todo... La creatividad durante mi embarazo; 4. Preguntas, críticas y reflexiones sobre la etapa prenatal a nivel social; 5 . La importancia de que la mujer tome consciencia de lo que sucede a nivel psico-emocional en su embarazo y lo elabore; 6. Arteterapia pre-natal, objetivos; 7. Acompañar a una pareja en el proceso de paternidad y maternidad; 8. Ejemplo de un caso de arteterapia prenatal en sesiones de pareja en consulta privada en Barcelona: el rechazo y aceptación de la propia maternidad; 9. Formación con la voz, la música y el canto prenatal, bases metodológicas; 10. El equipo y el curso; 11. Los talleres en grupo; dos experiencias interdisciplinares y sensoriales; 12. Testimonios del curso "Recursos creativos para la etapa prenatal" en Madrid 13. Experiencia en la Universidad de Zaragoza, en Jaca, taller para

1 Arteterapeuta interdisciplinar especializada en el ámbito de infancia y familia, casos de adopción, acogida y maternidad. Pintora y maestra de artes plásticas. Iniciación al canto prenatal. Coach personal para artistas, terapeutas, emprendedores y empresas familiares.

E-mail: info@annafreijomil.com

www.annafreijomil.com 
alumnos del curso de verano de musicoterapia y arteterapia; 14. Conclusiones finales; 15 . Bibliografía y referencias.

Cómo citar: Freijomil Reverter, A. (2016) Arteterapia y musicoterapia en la etapa prenatal, paternidad, maternidad y post-parto. Recursos creativos para profesionales que les acompañan, en Arteterapia. Papeles de arteterapia y educación para inclusión social 11, 163-183.

\section{Introducción, el encuadre autoetnográfico: una forma narrativa de generación de conocimientos}

El marco de dicho trabajo de investigación es cualitativo, y una forma de escritura y presentación de resultados, denominada autoetnografía, un encuadre alternativo, es por ello que este escrito tiene cierto carácter autobiográfico. Entre otras, una manera de ver a la autoetnografía es ubicándola en la perspectiva epistemológica que sostiene que una vida individual puede dar cuenta de los contextos en los que le toca vivir a esa persona, así como de las épocas históricas que recorre a lo largo de su existencia (Blanco, 2012).

El motivo de escoger esta modalidad es debido al momento histórico que estamos viviendo en España, en donde la arteterapia no está aún reconocida como profesión. Las experiencias que aquí expongo han sido pioneras y están enmarcadas en una situación y contexto muy concreto, por lo que considero necesario abordarlas desde un enfoque cualitativo y narrativo que pueda dar cuenta de la experiencia. Desde la experiencia y las observaciones del conocimiento situado (Haraway, 1995) expongo aquí esta manera de investigar la cual me parece apropiada para dicha situación social y mi experiencia vital. La posición más extrema del aprendizaje situado sostiene que no sólo el aprender sino también el pensar es situado y que por lo tanto debería ser considerado desde una perspectiva ecológica. Tal posición se basa en el trabajo de Gibson (1986) que enfatiza que se aprende a través de la percepción y no de la memoria. Considero básico aclarar este encuadre teórico y metodológico escogido, una forma de narrar y escribir más coloquial en parte, desde la humilde experiencia y crisis existenciales, que es desde donde me motivé para abordar e investigar a través del arteterapia y musicoterapia prenatal y hacer de ello mi campo de trabajo. No soy investigadora ni escritora profesional por lo que me resulta más cercano y ameno incluso para el lector esta aproximación a dicho aprendizaje personal y profesional. La investigación recorre varias etapas, empezando por el porqué de la misma, qué me motivó a hacerlo. A partir de aquí narro experiencias propias y ajenas, y como desde éstas tomo conciencia de situaciones a nivel social que afectan a la mujer. No es una narración lineal, si no que reflexiono a través de las observaciones de algunos casos aquí expuestos y sobre mi experiencia, sobre el hecho de ser mujer, de la construcción de la maternidad, del acompañamiento asistencial que se le da a la mujer embarazada y de cómo estos cambios físicos, emocionales y psíquicos afectan a la mujer y a la relación de la pareja. Intento abarcar muchas cuestiones en poco espacio, y tengo la sensación evidente de que falta profundizar en algunas, precisamente por este motivo. Finalmente apunto propuestas concretas que pudieran favorecer un cambio de actitud social enfrente a estos temas, así como 
una visión colaborativa para conseguirlo. He aprendido mucho intentando plasmar lo que quiero comunicar, espero incite al lector a la reflexión y al auto-análisis. Mas allá no pretendo nada, pues ni las ideas nos pertenecen, el conocimiento es libre y yo tan solo he visto un camino. Sigo andando...

El origen que desencadenó esta investigación, fue a partir de mi embarazo y maternidad, y a raíz de esta realidad, mi deseo de profundizar en esta etapa mediante el trabajo y acompañamiento con el arteterapia, inicialmente conmigo misma, y posteriormente con grupos, parejas y futuras madres, padres y profesionales que les atienden pues no conocía ninguna experiencia similar en aquel entonces. Este proceso me llevó a buscar y conocer a grandes profesionales que dedican su trabajo e investigación a la etapa prenatal, así como a leer sus investigaciones y prácticas que yo hasta ese entonces desconocía. Es mi necesidad vital compartirlas pues siento que en la sociedad actual hay mucho hincapié en el desarrollo temprano del ser humano para que produzca y consuma, sin prestar atención en lo verdaderamente importante, el desarrollo inicial del ser humano en el vientre materno, origen de cualquier trauma o bienestar futuro, ya que;

(...) las investigaciones científicas y psicológicas de estos últimos decenios confirman la intuición milenaria de las mujeres: el niño in-útero es un ser sensitivo, sensible, que reacciona, porque, desde su concepción, sus células se informan al mismo tiempo que se forman. Gracias a los poderes de la vida que hay en él, y por medio de materiales físicos, afectivos y mentales aportados por su madre-y, a través de ella, por el padre y el entorno- el niño prenatal construye las primeras bases de su salud, de su afectividad, de sus modos relacionales, de sus capacidades intelectuales, incluso de su creatividad. Esta educación prenatal, natural, es fundamental"2 (Bertín, 2005).

\section{Arteterapia interdisciplinar}

Empezaré explicando cual es mi base de trabajo. Mi formación en arteterapia es interdisciplinar, esto incluye disciplinas como el dibujo y pintura, el psicodrama, teatro terapéutico, expresión vocal y corporal, musicoterapia, la danza, la escultura, la fotografía, escritura creativa, las resonancias y devoluciones, etc., por citar algunas. Paralelamente siempre con una supervisión y acompañamiento de psicohigiene con una psicóloga y arteterapeuta. Es vital para nuestro trabajo tomarnos este espacio de psicohigiene en serio, y exponer nuestras dudas sobre nuestra actuación, y volver después a nuestra tarea que nos ocupa con ese grupo o paciente, más centrados, atentos y afinados que antes. Dicha metodología unida a la lectura de diversos libros afines al tema dan soporte a la base de mi trabajo como arteterapeuta. Considero que la lectura es importante en toda la etapa de formación

\footnotetext{
Marie-Andrée Bertín, directora honoraria de la escuela maternal encargada de la formación de maestros en los planos departamental y nacional, había observado correspondencias evidentes entre los problemas, o una aptitud particular, de ciertos niños y la forma en que su madre ha vivido el embarazo. Desde 1962 en Francia participa en la fundación de la primera Asociación para la Educación Prenatal. Desde 1991, preside la OMAEP (Organización Mundial para la Educación Prenatal) que agrupa 17 asociaciones nacionales que difunden en tres continentes los nuevos conocimientos sobre la vida prenatal.
} 
y práctica profesional como fuente de enriquecimiento y planteamiento de nuevos puntos de vista y reflexiones. Empecé mi camino como arteterapeuta en el centro privado Ludus de psicopedagogía, psicología y re-educación escolar de Palafrugell, Gerona, llevando casos derivados de servicios sociales, de niños y preadolescentes, conjuntamente con la psicóloga. Aprendí a colaborar con otros profesionales y conjuntamente en equipo. Después llevé grupos de arteterapia para familias (padres e hijos) en el centro cívico de Palafrugell así como clases de dibujo y pintura. Más tarde en una escuela pública y otra escuela rural, y en un instituto del Baix Empordà, ejercí de vetlladora3 y practiqué puntualmente y con el consentimiento de la tutora y equipo directivo del centro, sesiones individuales de arteterapia en horario escolar, en base a unos objetivos conjuntos acordados en reuniones de equipo juntamente con todas las instituciones implicadas: entre la dirección de la escuela y la psicopedagoga del centro, el CSMIJ; Centro de Salud Mental Infanto-Juvenil, el EAP; Equipo de Asesoramiento y Orientación Psicopedagógica y el EBAS: Equipo Básico de Atención Social. A raíz de todas estas experiencias yo me empecé a cuestionar el porqué había tantos niños con problemas. ¿Dónde están los orígenes de estos síntomas? ¿Se pueden evitar? Esto me llevó a pensar que tal vez tendríamos que regresar al origen y revisar cómo vinimos al mundo.

\section{Cómo empezó todo... la creatividad durante mi embarazo}

"El arte no es sino la expresión de nuestro sueño, el que más se entrega a ellos es el que más se acerca a su verdad interior." Franz Marc (Pintor alemán)

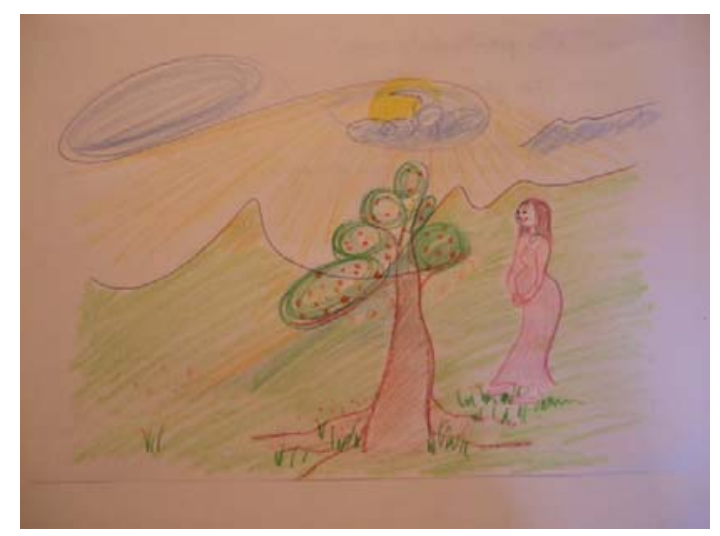

Figura 1: Dibujo realizado durante el segundo trimestre de mi embarazo, forma parte de mi diario arteterapéutico de mi embarazo. Le acompaña una poesía, cito

3 Vetlladora; figura profesional que acompaña dentro del aula a un alumno (ya sea en la etapa infantil, primaria secundaria o instituto) con NEE (niños con necesidades educativas especificas, LOGSE 1990) porque se considera que necesita una atención especial con dificultades específicas de aprendizaje, por sus altas capacidades intelectuales, por haberse incorporado tarde al sistema educativo, o por condiciones personales o de historia escolar..." (art. 71.2). Aquel que requiera, por un periodo de su escolarización o a lo largo de toda ella, determinados apoyos y atenciones educativas específicas derivadas de discapacidad o trastornos graves de conducta". (art. 73) 
solo una parte "Todo florece, todo crece, todo evoluciona, son los frutos de la vida, que me colman de alegría. Es la naturaleza la que me enseña los procesos de la vida, y a abrazar los frutos que llevo en mi vientre" (Freijomil, 2008).

En febrero del 2008 me quedé embarazada, la experiencia de ser madre no solo me llenó de felicidad, si no que me hizo madurar y darle una nueva perspectiva a la vida. Fue un embarazo muy esperado y deseado por mi pareja y por mí. Durante mi embarazo, que fue muy bueno, alternaba mi trabajo de vetlladora con mis pacientes de arteterapia en mi consulta en Begur, Gerona, trabajaba principalmente con mujeres y parejas en situación de crisis. Fue a raíz de mi propia maternidad que sentí que una etapa de tantos cambios y intensa no podía pasar sin ser abordada con el arteterapia. Empecé a leer algún libro de maternidad, pero al poco lo dejaba. Sentía que abordaba solamente ciertos aspecto físicos y psicológicos, así como de salud y cuidados médicos. Pero yo sentía que faltaba algo más. Mientras tanto empecé a llevar a cabo mi propio diario creativo, allí dibujaba mis sensaciones, a veces también pequeños poemas espontáneos, y así fue como poco a poco se convirtió en mi espacio y refugio de emociones, a veces tan nuevas y maravillosas, pero a veces también asomaban miedos y preguntas. De ahí, de estas necesidades no respondidas ni atendidas, surgió mi necesidad de crear un curso dirigido a las familias y a profesionales del ámbito sanitario (médicos, enfermeras, comadronas, ginecólogos, pediatras, psicólogos, etc.), del ámbito educativo (maestros, pedagogos, etc.), del ámbito social (educadores o integradores sociales, mediadores, terapeutas ocupacionales, etc.), así como terapeutas, doulas y cualquier persona interesada en profundizar en la etapa prenatal. Un curso de recursos creativos para padres primerizos o no. Empecé a gestar a la vez que gestaba mi bebé, un proyecto que iba cogiendo forma, a la vez que yo iba experimentando conmigo y con otras madres que quisieran formar parte de un proyecto piloto, arteterapia durante la etapa prenatal. Entonces en el año 2008, cree un blog titulado "embarazo consciente y creativo" haciendo pública la importancia de esta etapa y del acompañamiento en la etapa prenatal, y postparto (Freijomil, 2008). Esto despertó el interés en otros profesionales que desearon abordar también el tema con arteterapia y acudieron a mí para tener una aproximación a este método y visión. Posteriormente al nacimiento de mi hija, a medida que a poco a poco pude ir recuperando espacio y tiempo para mí y para volver a hacer cursos de corta duración y conferencias, la primera de ellas sobre este tema fue el lunes 15 de Febrero del 2010 a las 19h00, en Casa Asia, en Avenida Diagonal 373 de Barcelona, en colaboración con la Asociación Yoga para Nacer y Crecer. Mientras estuve embarazada practiqué yoga prenatal, y viendo sus beneficios, quise colaborar con esta asociación. yo misma observaba mi proceso, aunque sin mucha distancia, pero sí con plena sinceridad. Pero eso no era suficiente, necesitaba la justa distancia para ser acompañada, como diría Winnicott. Durante el tiempo que estaba gestando este proyecto y mientras realizaba los talleres de arteterapia prenatal, asistí a una psicóloga, pedagoga y mediadora de Girona, Araceli Pérez Poza, presidenta de la junta del Colegio de psicólogos de la Delegación Girona durante los años 2011 y 2015, así como fue la presidenta del Fórum Asociación de los Colegios Sanitarios en el 2014-2015. Me acompañó en un proceso bastante solitario de liderar una iniciativa en la que sabía que era muy importante encontrar 
a profesionales afines a mí, con la mente abierta, colaborativa, y emprendedoras para hacer este proyecto realidad. Araceli Pérez fue de gran apoyo tanto a nivel profesional como personal, de lo cual le estoy muy agradecida.

\section{Preguntas, críticas y reflexiones sobre la etapa prenatal a nivel social}

\section{Paternidad, maternidad y vínculos}

Primero reflexioné sobre los distintos vínculos que pueden existir entorno a la etapa prenatal, es decir, cabe la posibilidad que sea desde hombre-mujer, mujer y mujer, hombre y hombre, familia mono-parental, madre adoptiva, madre de acogida...por citar algunos. Así como hijo biológico, adoptivo o de acogida. Existen diferentes roles y vínculos posibles. Considero importante no encasillar el vinculo prenatal a solo una forma concreta, pues si no estaríamos excluyendo a una parte de la sociedad, a la cual también me dirijo. He tenido la oportunidad de entrar en contacto con diferentes de los casos mencionados, y he detectado que muchos tienen ciertas necesidades que la sociedad no atiende. Hay unas carencias a nivel social que considero necesario destacar, así como algunos posibles factores externos y peculiaridades de dichos vínculos que deberíamos tener en cuenta:

- Falta un acompañamiento psicoemocional y terapéutico especializado durante todo el proceso en la etapa prenatal, en la etapa de una adopción o acogida puntual o permanente. Pues a menudo hay situaciones y emociones muy intensas y variadas que quedan sin ser acogidas ni elaboradas ni integradas en la vida diaria de dichos vínculos.

- Hay una dificultad en los vínculos de relación de pareja o mono-parental de aceptar ciertos cambios (tanto externos como internos) algunas costumbres y hábitos en el día a día, como puede ser la disminución de la vida social, etc., que pueden causar una cierta ansiedad o preocupación. Por ejemplo puede darse el caso que se planteen decidir si la madre o el padre dejará o no el trabajo para dedicarse al bebé, o cómo conciliar la vida familiar y profesional, también son factores de mucha ansiedad (Cánovas, 2010).

- También suele suceder que la mujer tenga el temor a ser rechazada por la pareja por sus cambios físicos, los pechos a veces se caen más al amamantar al bebé durante un periodo largo de tiempo, pueden aparecer estrías, puede engordar, por citar algunos ejemplos. Puede haber también una disminución del deseo sexual, lo cual afecta a ambos miembros de la pareja de formas distinta. Sentirse menos deseada afecta a la autoestima de la mujer y por ende a la relación de pareja. Poder abordarlo con arteterapia me parece fundamental para que la autoestima y bienestar emocional sea fuerte y se acepten los cambios físicos como algo natural en la vida.

- El sentimiento compartido de madres primerizas de enfrentarse a lo desconocido. Ese desconocido a veces se puede hacer abrumador. Los miedos son humanos y en muchas madres existían distintos miedos; miedo a perder el 
bebé, miedo al dolor, miedo a los cambios físicos...etc. transitar el miedo y ver que se puede sentir y superar favorece un estado de ánimo más relajado que a la vez favorece al bebé, ya que se segregan endorfinas.

- La depresión postparto, y el sentirse incomprendidas. Muchas madres que han asistido en la consulta o en cursos me compartían que en su depresión postparto a veces se las tachaba de sensibleras, caprichosas o neuróticas. Se sentían muy solas y sin entender que les ocurría. Es importante escuchar y acoger este periodo que a veces ocurre, y si puede ser, anticiparse para evitarlo.

- Acoger cierta revolución creativa interna que despierta en ocasiones la maternidad. Ser madre, en mí, despertó una fuerza antes desconocida, una capacidad creativa mucho mayor. Muchas madres me comentaban que sentían capaces o con ganas de crear proyectos, empresas, o simplemente más inspiradas para explorar sus facetas artísticas a veces desconocidas. Me parece interesante que se pudiera dar espacio para que esto pudiera ser así.

- A partir del embarazo la mujer puede tener más contacto con la feminidad y que significa para ella. Así como ella se replantea a menudo el vínculo con la propia madre (esté viva o no) y como éste se re-significa. Este proceso afecta a la psique de la mujer de distintas maneras dependiendo de cómo sea el vínculo con su propia madre. Es interesante poder trabajarlo arteterapéuticamente. En mi caso por ejemplo descubrí que mi feminidad no era solo dulce, bella y serena, sino que también era fuerte, salvaje y valiente. En mi representó el principio de un nuevo empoderamiento a nivel personal. También sané ciertos aspectos con mi vínculo materno y afiancé aún más mi vínculo y mi amor por mi madre desde una nueva perspectiva.

- Una nueva sensibilidad. A menudo muchas madres así lo viven y no es fácil de encajar su nueva realidad interna a la realidad anterior, y a su realidad externa. Hay cosas que se sienten que pueden ser complejas de explicar, sin embargo, el ser madre, como en todos los mamíferos, despierta un sexto sentido de alerta y sentimiento de protección hacia su bebé. Poder expresarlo es muy liberador.

- El sentimiento de exclusión de la pareja por la llegada del bebé o por las constantes atenciones a la madre a veces sin querer ocurre, aparecen los celos de la pareja, en muchos casos de mi consulta las parejas expresaban un aumento de discusiones, debido a este tema. Encontrar tu lugar en esta nueva relación vincular es importante para una buena comunicación entre la pareja.

Cabe destacar cierto cambio social, y es la posibilidad que actualmente la pareja puede estar más implicada en diferentes momentos del embarazo (pruebas medicas, clases de preparación al parto, etc.) y del nacimiento de su futuro hijo, así como pedir baja por paternidad (esto último ya es más reciente). No hace tantos años, el padre prácticamente solo esperaba el nacimiento en una sala adjunta, le decían si era niño o niña y poco más. Pero aún queda mucho camino y aquí es donde creo que el arteterapia podría dar respuesta a lo mencionado anteriormente.

Pues, ¿tenemos una sociedad que nos enseña a ser madres y padres? Partimos del ejemplo de nuestros padres y madres (si los hemos tenido) o de los parientes más cercanos, o aquellas figuras que nos han servido de modelo. Cada uno aprende 
como puede. Es importante observar que según el psicoanálisis, tenemos unos patrones establecidos, en cuanto a comportamiento aprendido por imitación, y estos nos gusten o no, los repetimos. Pero podemos tomar conciencia de ellos con un apoyo psicológico, y afrontar aquellos patrones que no nos convienen para nuestro desarrollo y felicidad así como para los que nos rodean. He observado que el alto índice de estrés después de la venida de un nuevo miembro a la familia y por los cambios que acontecen, (ya que deja de ser una relación de a dos, si no de tres, cuatro...), muchas parejas se han acabado separando entre el año y los tres años después de tener un bebé. Tras nacer el bebé muchas parejas sufren crisis, a veces algo tan deseado y esperado como un bebé, trae consigo situaciones para los que no están preparados, y es normal, no lo estamos. Y aunque sea el segundo o tercer hijo, no importa, nunca es igual. Por ello creo en que la base para una sociedad más unida, es empezar trabajando el vinculo psicoemocional a pequeña escala. Y poco a poco, y reforzando y sanando nuestros patrones y vínculos entre hombres y mujeres, seamos capaces de tejer juntos relaciones de comprensión, igualdad, respeto, amor, y libertad. Como dijo el Dr. Michel Odent, obstetra, "La calidad de las sociedades futuras se asienta sobre la calidad de vida de todos los futuros padres" (Odent, 1984). Y es que la educación empieza antes del nacimiento, tal y como dice el Dr. Frederick Wirth, neonatólogo, profesor en la Escuela de Medicina de la Universidad de Tufts explica que al final de la $12^{\mathrm{a}}$ semana la totalidad de las neuronas del bebé ya se ha formado para el resto de su vida. (Wirth, 2001). Os invito con todo ello a reflexionar sobre cómo nos vinculamos, y sobre qué tipo de sociedad estamos creando en base a los vínculos que establecemos y la calidad de éstos.

\section{La importancia de que la mujer tome conciencia de lo que sucede a nivel psicoemocional en su embarazo y lo elabore}

La mujer embarazada está en un periodo de su vida en que la palabra CREACIÓN toma un nuevo sentido en su interior y su exterior. Internamente son momentos en que su cuerpo está CREANDO al bebé en gestación, a la vez que externamente se van observando los cambios que produce esta transformación interna. La creación interna no está desligada de la creación externa. Una idea se crea a nivel mental, y a su alrededor se crean unas emociones que se materializan en un objeto o un acto. A veces olvidamos que todo lo que pensamos y sentimos, tiene una repercusión en nuestro cuerpo y en nuestro entorno. Es importante que la mujer embarazada sea consciente de lo que siente y piensa durante este periodo de gestación, ya que repercute, positiva o negativamente en el bebé. Las emociones de la madre se transmiten al bebé a través de las hormonas. Cuando la madre experimenta una situación de estrés, se segregan catecolaminas, entre las catecolaminas encontramos la adrenalina y la dopamina. Cuando la madre experimenta amor, ternura y tranquilidad, y comprensión, estimula las endorfinas y segrega oxitocina. Odent aboga por medicalizar menos el parto y "mamiferizar" el parto observando necesidades básicas que compartimos con todos los mamíferos. Las hembras necesitan sentirse seguras y que su nivel de adrenalina sea muy bajo para dar a luz, pues si esta siente que hay un depredador o un peligro cerca, segregará adrenalina para poder defenderse y retrasará el parto para cuando se sienta más segura. Los 
mamíferos necesitan sentirse seguros y no observados para dar a luz. (Odent, M. 1984).

Al escucharse a sí misma y ser consciente de sus emociones, la mujer inicia un proceso creativo y terapéutico que le ayuda a expresar y transformar sus vivencias para que consiga repercutir positivamente al bebé en gestación. Sin este proceso nos quedaríamos a medio camino. Porque no es lo mismo saber qué es una montaña, que subirla. Con la experiencia de subirla, es entonces la cuando conoces. En este sentido, no es lo mismo saber cómo me siento, a explorar mis emociones. Si las exploro, puedo llegar a saber por qué aparecen, de dónde vienen, su origen y entonces empezar un proceso de comprensión, aceptación y transformación. Es muy importante que la mujer embarazada tome consciencia de qué le ocurre y busque un buen apoyo con arteterapia. Un embarazo bien acompañado es garantía de una mejor preparación para lo desconocido, esto incluso puede disminuir o eliminar completamente la depresión post-parto.

\section{Arteterapia pre-natal, objetivos}

El Arte-terapia se fundamenta en los procesos de creación y transformación. Consiste en el uso de diferentes disciplinas artísticas con fines terapéuticos. Se utilizan métodos terapéuticos creativos de lenguaje verbal y no verbal que facilitan la exploración de las emociones, el cuerpo y la mente, tales como la pintura, la escultura, el barro, la danza, representaciones teatrales, la expresión corporal y vocal, la música con diferentes instrumentos musicales, la fotografía, escritura creativa, foto-poesía, relajaciones, visualizaciones, afirmaciones, trabajo con mandalas, land-art, entre otros.

Los Objetivos y características más representativas del arteterapia aplicada a la etapa prenatal son:

- Concienciar de que lo que nos sucede a nivel psicoemocional, durante el embarazo es importante, sea lo que sea, tenerlo en cuenta y elaborarlo.

- Lo realmente importante es la evolución que hace la persona durante el proceso creativo, sin buscar que tenga importancia el resultado estético.

- Fomentar el auto-conocimiento, la reflexión, la creatividad y despertar las facultades del hemisferio derecho de nuestro cerebro.

- Disfrutar de la alegría en familia y expresarla creativamente

- Reforzar los vínculos entre Madre, Bebé en gestación y Padre o quien sea su apoyo emocional más cercano.

- Trabajar y mejorar la relación y la comunicación entre la pareja

- Nutrir a todos los niveles (físico, emocional, mental y espiritual) al bebé en gestación favoreciendo la producción de endorfinas.

- Aumentar la confianza y la serenidad durante todo el proceso del embarazo (sobre todo si anteriormente ha habido abortos)

- Poder crear un diario-álbum donde queda registrado todo vuestro proceso, un recuerdo especial para todos. 
- Ofrecer ejercicios creativos que puedan hacer en casa cuando lo necesiten, sea por estrés o felicidad, para una posterior elaboración con el arteterapeuta.

- Dar un espacio seguro y de confianza donde poder reconocer y expresar los sentimientos y pensamientos, sean cuales sean, sin emitir juicio sobre ellos

Para los profesionales que acompañan a mujeres gestantes, el propósito es que puedan tener herramientas creativas sencillas que puedan incorporar en su trabajo diario sin caer en la intromisión profesional. Es decir, facultar de sensibilidad hacia el arte para poder ofrecer puntualmente a alguna mujer gestante, un recurso creativo con una mirada más abierta que beneficie el vínculo entre ambos. Y si es su deseo, finalmente formarse como arteterapeuta y profundizar en el trabajo con el canto prenatal ya que puede beneficiar mucho en el parto.

\section{Acompañar a una pareja en el proceso de maternidad y paternidad}

"La maternidad es una crisis y oportunidad vital y revolución emocional" (Guttman, L. 2008).

El proceso puede ser compartido en un grupo de parejas o mamás, o también de manera privada e individual o en sesiones de pareja. Por mi experiencia creo que no hay una cosa mejor que otra, es lo que cada pareja necesite. A veces he alternado las sesiones grupales, con alguna individual para tratar algún tema personal más a fondo, y en total privacidad. En cambio a nivel grupal, reconforta saber que aquello que la mujer piensa que solo le pasa a ella, también le pasan a muchas otras mujeres. Puede vivir con mucha ilusión el embarazo, pero no por ello quizás esté exento de miedos o impaciencia, por nombrar algunas de las emociones más comunes. Se recomienda empezar las sesiones a partir del segundo mes de embarazo aproximadamente, una vez confirmado que el embarazo está fuera de peligro y todo está en orden. Uno no se convierte en padre o madre de golpe, es algo que hay que asumir, que hay que cultivar, y acompañar.

Hoy en día el único proceso de acompañamiento que existe para futuros padres, es la preparación al parto guiado por las matronas en los hospitales y clínicas. Y está muy bien, yo misma lo comprobé, en las sesiones que asistí, te enseñan a respirar y a cómo afrontar el periodo del expulsivo (nacimiento). Pero, ¿después? Están las revisiones a la ginecóloga para ver como evoluciona tu útero y otras cosas que pueden acontecer. Pero nadie me preguntó si nuestra relación de pareja se vio afectada, y cómo, nadie me acompañó en un proceso en que la feminidad toma un poder álgido, en que las emociones fluctúan mucho también y todas las mujeres nos sentimos novatas en el primer embarazo. Tuve que buscar este apoyo y acompañamiento por mi cuenta. Todo esto no es suficiente, ya que se aborda desde la perspectiva física del embarazo y parto únicamente, y aunque evidentemente existen profesionales muy bien preparados y empáticos ante las emociones de la madre y el padre, no entra dentro del programa diseñado por el ministerio de salud de nuestro país (España), abordar estas emociones, y menos desde una perspectiva artística y terapéutica. En otros si, por ejemplo en Francia el arteterapeuta, musicoterapeuta y profesionales como Marie-Laure Potel, psicofonista, han sido 
pioneras en abrir campo en este ámbito en grupos de embarazadas en la seguridad social (Marie-Laure Potel, 2001) Más adelante os hablaré de su aportación.

\section{Ejemplo de un caso de arteterapia prenatal en sesiones de pareja en consulta privada en Barcelona. "El rechazo y aceptación de la propia maternidad"}

Tanto en el primer embarazo, como en los sucesivos, hay muchos sentimientos que pueden aparecer debido a diferentes variables. En el año 2009 propuse un curso para parejas, un máximo de 3, para poder atenderlas mejor. Al final trabajaron dos parejas juntas todo su proceso de embarazo, con situaciones bien distintas. Citaré el caso de una de ellas, Pepe y Julia, (nombres ficticios) no eran padres primerizos, aun y así, se enfrentaban a un miedo que les perseguía como una sombra; la posibilidad de otro aborto. Ella, embarazada del segundo hijo, y su marido vinieron a mi consulta cuando la madre estaba de cuatro meses y medio, y en las primeras sesiones de arte-terapia prenatal junto con su marido, Julia expresó sus miedos; miedo perder a su madre gravemente enferma de cáncer ya que podía morir, y miedo a perder al bebé. Estaba muy nerviosa y con riesgo de aborto durante el primer y segundo trimestre por el gran estrés que sufría en su trabajo, dijo que estaba saturada de responsabilidades y presión y que no se atrevía a pedir la baja por miedo a perder el trabajo. Todo ello le creaba un exceso de estrés que no podía sobrellevar. Le habían programado un parto por cesárea. En esos momentos lo primero que abordamos era reconocer el origen del estrés e intentar canalizarlo mediante la creatividad y técnicas de relajación y visualización para que se comunicara con su bebé, entre diferentes técnicas, usábamos un CD guía llamado "Vitaminas de Luz, el lado invisible de la gestación" de la autora Carmen Santiago (Santiago, C. 2000). Se trabajó para fomentar la tranquilidad y la positividad. También usé algunos ejercicios del libro "El vínculo afectivo entre la madre y el niño que va a nacer" (Verny Y Weintraub, 2008). En esa comunicación musical y de relajación mental con su bebé, reconoció entre lagrimas que, lo deseaba tanto y a la vez tenia tanto miedo a perderlo, que no quería hacerse ilusiones, y por ese motivo, por si acaso lo perdía, internamente hacia como si no estuviera embarazada, no le hablaba, así si lo perdiera, no le dolería tanto, pensaba ella. Reconocer que lo estaba rechazando fue duro, pero fue un primer paso para ir al siguiente: decidir si quería establecer comunicación o no. Finalmente decidió sí hablar a su bebe, y decirle qué le pasaba, y que lo sentía, que él no tenía la culpa, que ella estaba muy temerosa. En la comunicación mediante las relajaciones, el bebé se movía más que nunca. Ella empezó a sentirlo, a vivirlo, y a aceptar su embarazo, en vez de rechazarlo y empezó por primera vez a los cuatro meses y medio de embarazo, a alegrarse y disfrutarlo. Pero entonces apareció otro sentimiento de culpa; “¿Está bien alegrarme por la venida de mi bebe estando mi madre enferma?" Comentó Julia en una sesión mientras dibujaba. Pensaba que delante de la madre enferma no podría sentirse feliz por su embarazo, lo veía como una falta de respeto ante la enfermedad de su madre. Poco a poco fue reconociendo uno a uno todos sus miedos, y los fue afrontando, paso a paso, y a su ritmo. Y puso todo en su lugar. A raíz del proceso de varias sesiones, ella fue relajándose, transformó sus miedos en confianza, se permitió ser feliz y alegrarse por la llegada 
del segundo hijo, solicitó la baja laboral y a partir de ese momento mejoró su estado de salud en su embarazo y encontró en las sesiones de arteterapia prenatal un espacio reconfortante, y donde cargarse las pilas, como decía ella, y en ese proceso el bebé se posicionó correctamente y nació de forma natural sin cesárea, contra todo pronóstico médico. ¿Quizás fue fruto de su cambio de actitud positiva y de comunicarse con el bebe? Pepe y Julia tienen un buen recuerdo de las sesiones, hicieron trabajos creativos con mandalas, barro, cartas a su bebe, entre otros, que ayudaron a la pareja a escucharse, a expresarse y compartir fuera lo que fuera y con ello conseguimos reforzar los vínculos de pareja, beneficiando por descontado al bebé en gestación. A menudo en las sesiones utilizo libros como material de apoyo, en el caso de ejercicios de poemas y cartas, les mostré el libro "A mi hija con amor, sobre las cosas importantes de la vida" (Schutz, 1990). Pues a veces, cuando invito a escribir una carta, un poema, algo, la persona se bloquea, pensando y expresando en voz alta "yo no sé, yo no soy escritor/a...". Libros sencillos como este ayudan a ver que cualquiera puede hacerlo, con la guía adecuada. Les ofrecía bibliografía por si quería profundizar en el trabajo terapéutico que estábamos haciendo, como por ejemplo, en lo relativo a la comunicación musical con su bebé, pues mejorar la comunicación de ella con su bebé, era uno de los objetivos principales. Por ese motivo les mostré el trabajo de Gabriel Fabián Federico, musicoterapeuta, donde explica y cito:

“(...) voy a explicar los efectos los efectos de la música en relación con el bebé, de que forma esta puede ayudar al parto y, fundamentalmente, a la relación que se está gestando entre ambos. El presente trabajo se sustenta en la base teórico-práctica adquirida en el campo de la estimulación prenatal con música, desde mediados de 1995, con más de 1.200 mamás y cerca de 1.350 bebés, y en los intercambios profesionales realizados con investigadores colegas, médicos obstetras, genetistas, parteras, etcétera. De este modo, pude desarrollar una técnica especifica y encontré diferentes aplicaciones para la musicoterapia, dentro de la obstetricia" (Federico, 2007).

En este sentido es donde yo veo que tenemos modelos de cómo el arteterapia puede iniciar un camino de investigación en el campo de la obstetricia, para ello falta que centros médicos tanto privados como públicos y hospitales, entre otros, que nos den acceso a trabajar con futuras madres y padres y documentar todo para poder extraer posteriormente datos y conclusiones. Y paralelamente luchar para que se logre nuestro reconocimiento social como arteterapeutas.

A mitad del proceso Julia se dio cuenta de que su marido la apoyaba en todo y que la valoraba por lo fuerte que era, a la vez que la mimó y compartió con ella todo el proceso. Fue un gran alivio para ellos encontrar un lugar donde poder expresarse con sinceridad sin ser juzgados, siendo acogidos con cariño y acompañados en lo que podría haber sido una etapa muy dura y con mucho sufrimiento sin apoyo, esta se convirtió en un gran aprendizaje que les hizo crecer como personas y como pareja y, sobretodo, transformar los miedos en fuerza para seguir avanzando con alegría. 


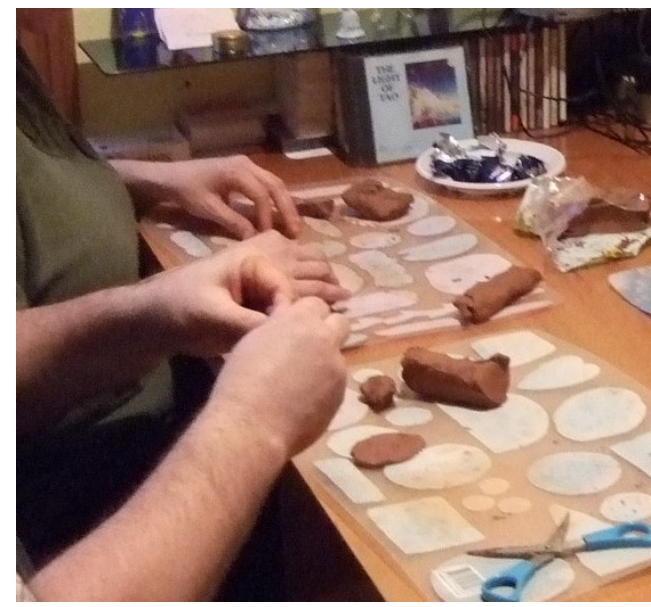

Figura 2: Marido y mujer trabajan con barro.

Marido y mujer trabajan con barro para trabajar el vínculo nuevo que se está creando entre ellos. Consigna de partida: ¿Cómo está cambiando tu vínculo respecto a tu pareja? Represéntalo. Después hubo una explicación mutua sobre el proceso y sus obras, y un reconocimiento y valoración mutua, que hizo que la mujer pudiera relajarse más y confiar más en el apoyo de su pareja. La mujer se sorprendió de la figura que hico su marido, era un sol. Él explicó que veía a su mujer más bella que nunca, cálida como el sol y que disfrutaba mucho de ella a su lado. Ella hizo un corazón y símbolos de música, dijo que empezaba a escuchar su corazón cómo cantaba y que esto le hacía sentir bien, y más relajada con su pareja. Que había dejado de estar arisca y apática, y que ahora a menudo estando en casa, escuchaba música y cantaba, sintiendo su bebé como respondía moviéndose a dichos estímulos.

Posteriormente después de unos meses de nacer el bebé, hicimos algunas sesiones post-parto, de la pareja con su primer hijo de 5 años, ya que aparecieron los típicos celos que a veces a aparecen, del niño hacia la nueva atención que tenían a su hermana. Trabajamos los tres juntos y fue muy gratificante ver cómo los celos se disipaban y se le ofrecía al niño un saberse querido igual. Ver a sus padres dibujar con él, escribir con él, le hizo sentirse importante y que sus emociones eran tenidas en cuenta. No hubo críticas por los celos, se acogió con amor, diversión y trabajando mucho el vinculo familiar.

\section{Formación con la voz, la música y el canto prenatal, bases metodológicas}

Marie-Laure Potel, Psicofonista desde 1984, se ha centrado sobre el desarrollo del canto prenatal. Su formación inicial de música: piano, voz, djembé, y su ejercicio profesional se ha desarrollado sobretodo en el ámbito médico. Dirige los talleres de Canto Prenatal en diferentes Hospitales-Maternidades en París: "Les Lilas", y "Les Bluets", los talleres de canto madre-niño en diferentes asociaciones y grupos de cantos psicofónicos. Tal y cómo nos explica Marie-Laure Potel, el Canto Prenatal es una práctica que se basa en la psicofonía, creada por Marie Louise Aucher, la 
cual estudió e investigó la relación entre los sonidos y el cuerpo. "Todo el cuerpo está receptivo para emitir sonidos y también para recibir vibraciones y el bebé en gestación también se impregna de vibraciones". A partir de 1975 se desarrolla El Canto Prenatal, basado en la consciencia de la vida intrauterina y la influencia de la voz en el desarrollo del bebé. Durante el embarazo el cuerpo de la mujer cambia y su voz también. El canto le permitirá sentir su cuerpo de una manera jovial y placentera. La técnica ofrece unos ejercicios muy precisos donde el cuerpo, igual que un "instrumento musical", se podrá "afinar" y producir las vibraciones necesarias para favorecer la relación madre-hijo. Los ejercicios corporales propuestos se acompañan con sonidos. Con las vocalizaciones se ejercita la respiración, la tonicidad muscular y la dinámica corporal. Estas propuestas permiten a la mujer descubrir el potencial vibratorio de la voz y de los sonidos y servirse para su bienestar físico-psíquico durante el embarazo, parto y post-parto.

Beneficios de la práctica del canto prenatal (extraído de la formación que hice con Marie-Laurel Potel, 2010):

- A nivel físico, cantar ayuda a mejorar la postura y la respiración, favorece la conciencia corporal y es un buen recurso en caso de pequeñas dolencias físicas.

- A nivel psíquico/ emocional es un medio sencillo y privilegiado para expresar y elaborar sentimientos y emociones propias de esta etapa, así como para tomar conciencia y aceptar los cambios que la paternidad y la maternidad conllevan (apoyados por el clima de contención que se genera en el grupo, en el cual podemos compartir sentimientos e inquietudes sintiéndonos respetados $\mathrm{y}$ apoyados).

- Para la comunicación con el bebé, el canto es uno de los medios más especiales y directos que tenemos. El bebé percibe la voz de la madre desde sus primeras semanas en el vientre (primero como vibración y más adelante como sonido). Hablar y cantar para él nos permite gestar un vínculo temprano y sólido con nuestro bebé.

-La voz puede ser además una gran aliada en el trabajo de parto y nacimiento: es un medio analgésico natural que posee el cuerpo (ligado a la producción automática de endorfinas), favorece la dilatación, aumenta la fuerza para empujar y nos permite estar más en contacto con las sensaciones y las necesidades del momento, tanto de la madre como del bebé.

Yo misma he comprobado los efectos del canto prenatal en mi primer embarazo. Tuve la suerte de que mi profesora de yoga trabajaba mucho con la voz, el canto de manteas y sonidos libres para favorecer el proceso del parto. El hecho es que yo me sentía muy bien cuando cantaba y creo que Iris, mi hija, también, pues estaba tranquila y la sentía bien. En el proceso de dilatación, hacia movimientos a nivel de pelvis con la pelota inflable, que había aprendido en yoga, y emitía sonidos junto con las respiraciones, que aliviaban mi dolor. Fue un parto muy largo y si no hubiera sido por todo lo aprendido hubiera sufrido mucho más. En mi parto canté, recité mantras junto a mi marido, no sé qué pensarían los médicos, ni las enfermeras, pero nos dejaron la libertad de expresarnos, y para mí fue muy importante. De hecho escogí este Hospital público de Santa Caterina de Salt, Girona por ser pionero en partos respetados y partos en el agua, así como de 
profesionales preparados para ello. Es en occidente que no está tan bien visto que las mujeres griten, canten o hagan sonidos durante el parto, cuando de hecho esto favorece mucho más todo el trabajo del expulsivo, como lo llaman en el ámbito médico. Entonces fue más tarde cuando me formé en canto prenatal nivel introductorio con Marie-Laure Potel, cuando visitó Palafrugell en el 2010, en l'Eix centro de pedagogía corporal, y así pude complementar el trabajo de Arte-terapia prenatal. Me ha dado muy buenos resultados, tanto a nivel grupal, pues se eleva el nivel de energía, ya sabéis, hay un dicho que dice "quien canta su mal espanta", y es cierto. A las mujeres que venían cansadas ese día, les cambiaba el rostro, su expresión era más relajada y feliz, su mente más positiva y en general nos lo pasábamos muy bien, a la vez que tomaban mucha conciencia corporal.

\section{El equipo y el curso}

Buscaba en España quien podría tener formación parecida y buscando encontré a Esther Santiago (psicóloga) y Myriam Chiozza, musicoterapeutas especializadas en las etapas pre y perinatal, y en ese momento miembros activos de ANEP (Asociación Nacional de Educación Prenatal). Desde hace unos años enfocan su actividad a la investigación, el estudio y la difusión de la importancia de la etapa prenatal y los beneficios de la voz en el embarazo y la crianza, acompañando grupos de apoyo para familias en Madrid y participando en congresos, talleres, cursos y formación para profesionales de diversas áreas. Contábamos con el aval y apoyo de ANEP, para difundir nuestro proyecto. Empezamos con las reuniones por skype, teléfono y también en persona en Madrid para ir dando forma a nuestro curso y aprender unas de otras. Era muy emocionante sentir la pasión que nos unía, despertar la sensibilidad y conciencia en torno a la maternidad y las artes. Aparte del diseño del curso, y redactar un único dossier con información teórico que repartimos a los alumnos, también repartíamos una ficha para cada alumno, donde a parte de sus datos personales para poder comunicarnos con ellos en próximos cursos o charlas informativas, les solicitábamos si nos daban su consentimiento para realizar fotografías y videos y explicábamos sus posibles usos; para utilizar en el caso de escribir un libro, publicarlo en nuestras webs, realización de trípticos informativos por poner algunos ejemplos. Creo que es importante ser muy cuidadoso pues he observado que actualmente muchos terapeutas cuelgan fotografías de sus cursos en internet, facebook o otras redes sociales, sin avisar o pedir permiso por escrito. Es vital conocer la ley de protección de datos y derecho de la propia imagen. Y siguiendo con el rigor dábamos un cuestionario inicial que nos daba una información de partida respecto a la situación personal y profesional del alumno, y al terminar el curso rellenaban otro cuestionario cualitativo para valorar el curso. En cuanto al contenido del curso introductorio a las posibilidades que ofrece el arteterapia y la musicoterapia y canto prenatal, lo enmarcamos dentro de una duración de 8 horas, en fin de semana; 4 horas de arteterapia donde se hacia una introducción a la teoría del arteterapia: sus orígenes, qué es, cómo se trabaja, su aplicación durante el embarazo y beneficios. Propuesta de un diario creativo prenatal. Ejercicios en pareja, otros individuales y otros en grupo. Y 4 horas de musicoterapia; Introducción a la teoría de la musicoterapia: sus orígenes, qué es, cómo se trabaja, su aplicación durante el embarazo y beneficios. En las dos 
disciplinas se usaron ejercicios, en más o menos medida, corporales, con el uso de la voz, el canto, la escritura, la pintura, relajaciones y la danza.

\title{
11. Los talleres en grupo; dos experiencias interdisciplinares y sensoriales.
}

\author{
“Todo arte es imitación de la naturaleza” Lucio Anneo Séneca (filósofo \\ romano)
}

\section{Experiencia piloto del curso "Recursos creativos para la etapa prenatal" arteterapia, musicoterapia y canto prenatal, en un centro de terapias de Madrid}

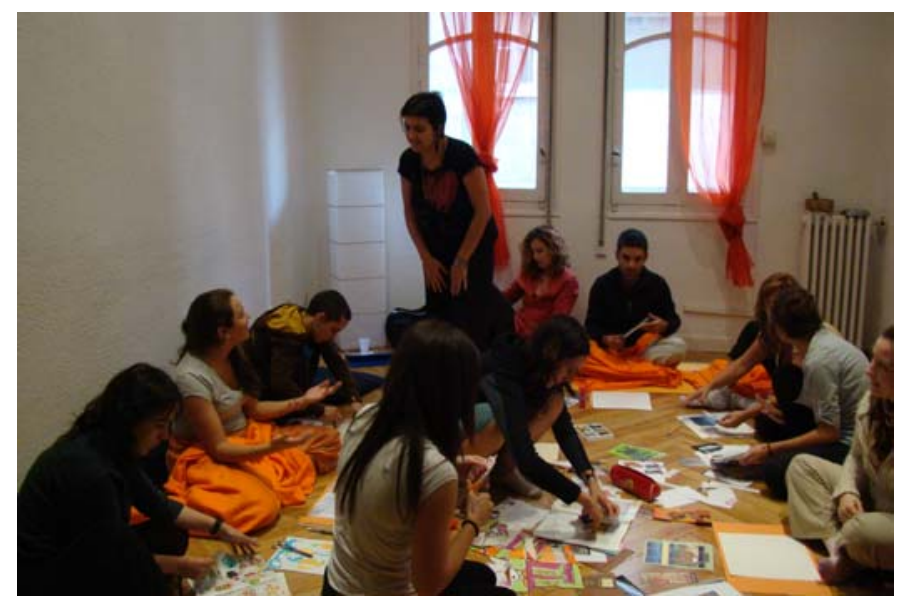

Figura 3: Ejercicio grupal de arteterapia. Iniciando un encuentro de escucha con uno mismo a través del dibujo espontaneo, reflejo del inconsciente. ¿Que surge? ¿Qué dice de ti? ¿Qué emoción produce en ti? ¿Cómo lo nombrarías?

Hicimos dos ediciones en el año 2010 y otra en el año 2011, con una media de unos 12 alumnos por curso aproximadamente. Los alumnos eran de edades distintas, desde estudiantes a futuras madres y padres, una madre adoptiva, otra madre soltera, a profesionales como dos matronas, enfermeras, una profesora de piano, danzaterapeutas, educadores sociales, musicoterapeutas, artistas, doulas, psicólogas, y psicomotricista en edad temprana, directoras de centros de terapias, una profesora de yoga prenatal entre otras. Como arteterapeuta centré mi trabajo en lo sensorial, a través de todos los sentidos, la exploración interna y externa y el trabajo con la pareja o acompañante. La disposición era en círculo sentada en el suelo, y sobretodo que estuvieran cómodos. Había ejercicios en grupo, otros por parejas y otros a nivel individual. El orden de los ejercicios tenía un sentido, pues se trata de que personas de procedencias muy distintas y que no se conocen entre sí, se las tiene que acomodar y hacer un espacio seguro y cálido para que puedan abrirse a compartir y jugar de forma autentica. Lo que se conoce como ejercicios de caldeamiento, para ir progresivamente acercándonos al prójimo y al resto del grupo en confianza. En algún ejercicio de pareja trabajaba la escucha y el ser 
acompañado y el dejarse acompañar, mediante la danza y la expresión corporal. Era bueno observar cómo afloraban los roles establecidos en la pareja, por ejemplo, una madre dominante y un padre que sentía que apenas podía colaborar en nada, él sentía frustración. Esto quedó claro en su danza y en su propia verbalización de lo sucedido en la danza. Nadie pensaba que algo aparentemente tan sencillo o inocente como una danza con una música de fondo, de base con sonidos de mar, con unas consignas claras, pudiera dejar al descubierto, actitudes y hábitos inconscientes establecidos entre la pareja y en cada uno de ellos. Otro ejercicio por ejemplo es realizar un mandala, no deja de ser un dibujo dentro de un círculo. El círculo es un tema recurrente, el bebé prenatal nada dentro del círculo del vientre materno, en un medio acuático, al igual que la música que seleccione de fondo. Todo está cuidadosamente seleccionado. El mandala sirve mucho, entre otras cosas, porque centra mucho nuestra atención, y focaliza esa atención allí donde queremos potenciar algo, sea una idea, una emoción o un mensaje positivo. Se trata de plasmar algo libremente para que actúe como un anclaje, y que la persona al mirarlo, le dé fuerza a eso que está contemplando. Es una manera artística y visual de decirle al cerebro, céntrate en eso. Otra propuesta creativa era un diario creativo durante el embarazo, lo empezaban en el curso pero la idea es que lo continuaran fuera de que él, en su casa. Es una manera de registrar lo que ocurre y como se vive, elaborar una historia y un dialogo para favorecer el vinculo y la comunicación entre madre y bebé prenatal. Evidentemente lo ideal sería que esto pudiera trabajarse mediante un acompañamiento arteterapéuticoterapéutico para elaborar lo que en este proceso suceda. Uno de los participantes del curso, José Juan Fernández Bocanegra, estudiante del máster de arteterapia en la UCM, le interesó tanto que decidió que quería hacer sus prácticas con mujeres gestantes. Le facilité el contacto con Fundación Madrina en Madrid, donde hacen una gran labor con jóvenes embarazadas en riesgo de exclusión social, y las ayudan en su proceso de embarazo y empoderamiento personal.

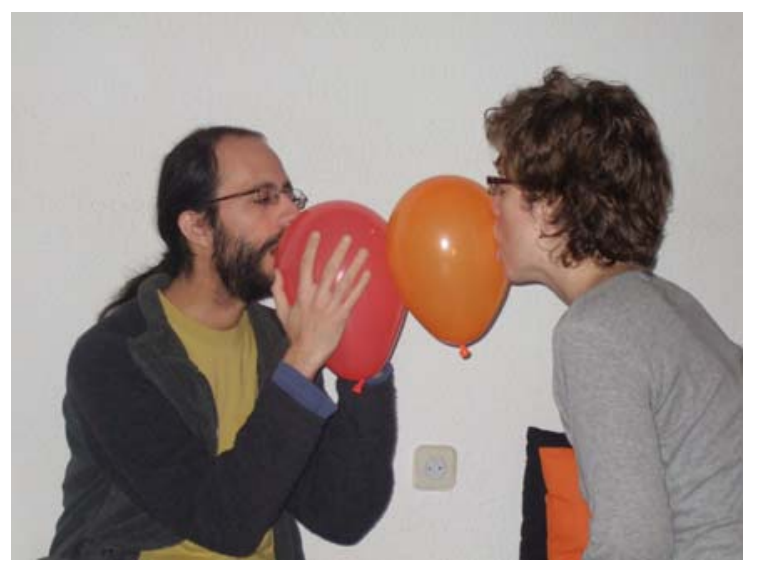

Figura 4: Ejercicio sonoro en parejas para percibir las vibraciones como si fuera el útero. La comunicación; emisión y recepción. Psicoterapia. 


\section{Testimonios del curso "Recursos creativos para la etapa prenatal" en Madrid}

Cito algunos comentarios de los alumnos al finalizar el curso:

- Tatiana, musicoterapeuta de Madrid: "Encuentro el curso muy interesante y necesario. Me gustaría alargar y profundizar en este tema aunque no estoy de momento embarazada, me servirá para cuando lo esté. Valoro el ambiente cálido que se ha generado en el grupo y la acogida de las profesoras"

- Anna, doula y artista de Girona. "Hay mucha creatividad y los conceptos están bien trabajados. La musicoterapia me era desconocida, por otra parte, me reencontré con la música"

- Mónica, pedagoga musical y futura musicoterapeuta de Zaragoza: "Me ha gustado todo de la arteterapia, desde los ejercicios a la puesta en común. Para ser solo 8 horas es muy completo. Me gustaría saber más información sobre investigaciones entorno esta etapa. Y sí, creo que algunas cosas podré aplicarlo a mi trabajo"

- Rosa, Matrona de Cantabria: "Me ha gustado mucho el clima, y lo eminentemente práctico y vivencial que es."

- Ana, psicóloga y psicomotricista en atención temprana, de Madrid: "Creo que si podré aplicar algo a mi trabajo pero creo que el curso debería ser de dos días para permitir asimilar los conceptos y las vivencias y digerirlas poco a poco. Me ha gustado la disciplina de la musicoterapia que desconocía totalmente, la gran cantidad de herramientas y posibilidades que ofrece."

- Marta, profesora de Yoga prenatal, de Madrid: "Me han gustado todos los ejercicios prácticos, en concreto el de arteterapia de acompañar a la pareja y dejarse acompañar y el de los globos y el sonido. Creo que lo podré compartir con mis alumnas de yoga prenatal. A nivel personal me ha enriquecido."

\section{Experiencia en la Universidad de Zaragoza, en Jaca, para alumnos del curso de verano de musicoterapia y arteterapia}

Había sido alumna de este maravilloso curso de verano en Jaca, realizado por la Universidad de Zaragoza, en el año 2007. A raíz de investigar y trabajar, madurar y ser madre, pensé que el trabajo de arteterapia prenatal debía de estar en las universidades. Así es como propuse a la presidenta de la Asociación Aragonesa de Musicoterapia y miembro del curso de verano, Virtudes Morcillo, que incluyeran unas horas de docencia a modo de taller teórico - vivencial y así fue como lo aceptaron y lo impartí el verano del 2011. De repente me encontré con un grupo de 40 alumnos. Siempre este curso tenía mucho éxito y sabía que sería todo un reto. La parte teórica la explique mediante un powerpoint y entregué un breve dossier impreso. La mayor parte fue vivencial. Despertó gran interés y la experiencia fue muy positiva para ambas partes. Fue un taller de apenas 2 horas y media, casi 3 , dentro de un apretado e interesante programa. Solo se pudo abrir boca, pero al menos se pudo poner sobre la mesa un campo de trabajo en que se que algunos de esos alumnos, continuaron investigando y trabajando sobre ello. 
Las universidades es un lugar donde se plantan muchas semillas, donde se despiertan conciencias, donde se invita a investigar. Ojalá más universidades vean esta necesidad de tratar este tema, ya sea en asignaturas, talleres, postgrados o cualquier otra modalidad de enseñanza.

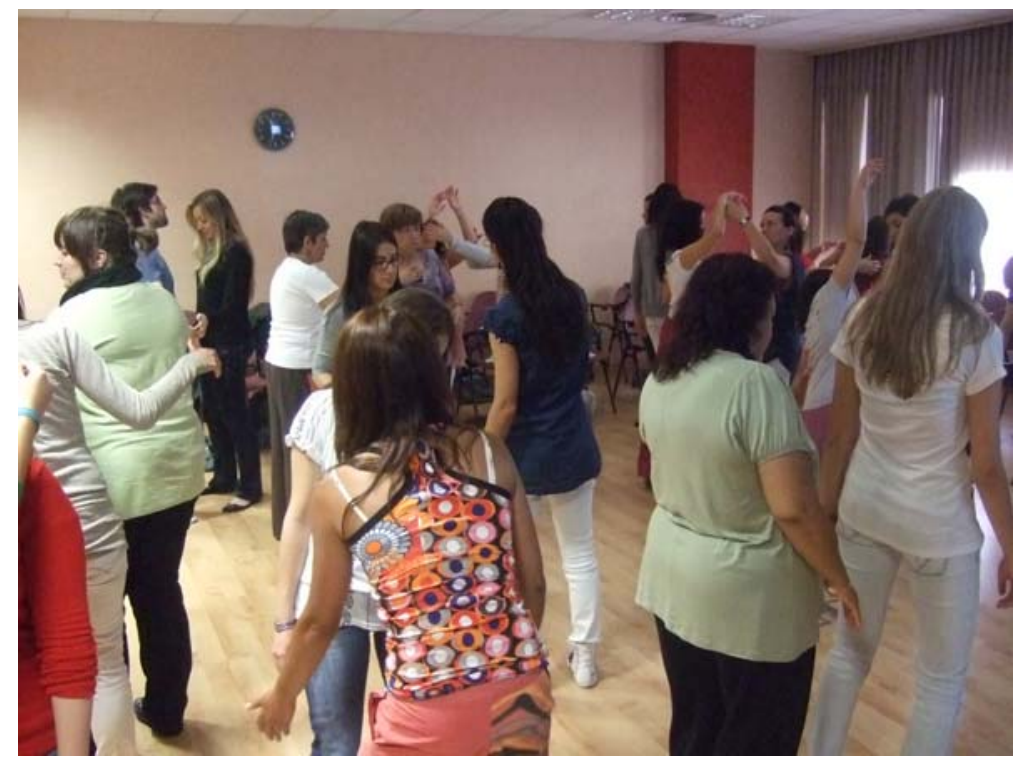

Figura 5: Ejercicio en parejas, las dos personas experimentan los roles de acompañar y ser acompañado mediante el trabajo corporal la música y la danza. La que se deja acompañar tiene los ojos cerrados, así trabajamos la confianza, y la que acompaña los tiene abiertos, así trabaja la atención y la percepción de las necesidades del otro.

\section{Conclusiones finales}

He intentado plasmar de forma resumida y clara mis experiencias y como estas me han hecho preguntarme y moverme a buscar respuestas y métodos dentro de la arteterapia, adaptando ejercicios aprendidos a los objetivos que se pretendían trabajar, así como intentando aportar algo nuevo. En mi viaje me he apoyado en la praxis de profesionales que en su día visualizaron un camino en el ámbito prenatal y a día de hoy ya nos han podido ofrecer resultados como es en el caso de la musicoterapia prenatal, la psicofonía, y el canto prenatal. Creo que todo en su conjunto nos puede ofrecer una visión de las posibilidades que ofrece el arteterapia, tanto en el periodo de antes del embarazo, durante y después del parto. Diría que se abre un camino muy virgen aquí en nuestro país, aún por explorar e investigar en profundidad. En otros países como Colombia Chile, Venezuela, Francia, y Estados Unidos, por citar algunos, ya están elaborando tesis, investigaciones y propuestas y desarrollando un trabajo al respecto, no solo a nivel de impartición de cursos sino también dentro del ámbito educativo y sanidad pública, desde hace más años que aquí en España. Me puse en contacto con algunos de ellos, me emociona ver como en otros países son fácilmente acogidas diferentes propuestas en hospitales o 
colegios. Incluso hubo arteterapeutas que me ofrecieron asistir como observador en sus talleres. Aquí nos falta aun ser más abiertos. En cuanto al tema central de la maternidad y los vínculos, somos cada vez más los profesionales que estamos reflexionando sobre el vínculo materno-filial, pues es hablar del vínculo a la vida misma. ¿Cómo nos vinculamos a la vida? ¿La amamos? ¿Tal vez la rechazamos, porque a nosotros también nos rechazaron en el vientre materno? Cómo me vinculo yo a la vida... gran pregunta. $Y$ es de hecho la base de nuestra existencia. ¡Cómo no tener en cuenta algo tan vital e importante! Tal y como sea nuestro origen y nuestro despertar en esta vida, será nuestro caminar. ¿Queremos andar despiertos o dormidos a nuestra sensibilidad? Algunos la llaman intuición, o valor intangible. El arte despierta en nosotros esa sensibilidad, nos abre los ojos aunque a veces duela, y nos da a la vez en antídoto contra nuestro dolor; se llama conciencia y decisión de cambio. Aprender a vincularme de forma equilibrada con el otro y conmigo mismo, nos puede cambiar la vida, enriqueciéndola. Por eso pongo tanta atención en este punto. Comparto mis observaciones al llevar los diferentes grupos, parejas y madres con las que he trabajado, en etapa prenatal para que cada uno tenga una idea general de lo que he vivido y como ello me ha cambiado y me ha motivado a seguir desarrollando teorías. Entre ellas la teoría de naturalizar la sensibilidad, palabra que a menudo ha estado unida a prejuicios y etiquetas que menosprecian una facultad para mi muy preciada, y la cual me ha ayudado mucho en mi labor de arteterapeuta, a saber ser empática y delicada acompañando a la madre, pareja o grupo, que estaba conmigo. Una maestra me hablaba un día de lo que la sociedad asume como natural, entre ello la violencia, que la vemos en muchas partes y ya casi no nos sorprende. Y que habría que desnaturalizarla, pues estamos muy acostumbrados a ella, tanto que tenemos la piel muy gruesa. La violencia existe muy camuflada también en el trato a la mujer embarazada, haciéndola tonta, o tratándola de neurótica por sus cambios hormonales, entre otras cosas, como puede ser la atención al parto, un gran tema. Una sociedad sana ha de naturalizar las emociones, y no la violencia, naturalizar el arte como vía de integración social y empoderamiento personal. El trabajo que propongo desarrollar es, a parte de seguir investigando, reflexionando y comunicando lo que se investiga sea de forma escrita y/o dando conferencias, es sobre todo una propuesta con carácter educacional y preventivo a nivel de salud psicoemocional. Creo que hemos de llegar primero a las futuras madres, y a las madres, crear grupos de apoyo y trabajo arteterapéutico y que vean la necesidad y los beneficios de esta práctica. Al tener grupos tendremos experiencia, y luego datos cualitativos y cuantitativos. Aprender de aquellos que ya nos llevan ventaja. Ir con todo ello a las instituciones, con un proyecto bajo el brazo, explicar, convencer, y conseguir que lo propongan, dentro del Area de Bienestar y Familia, por ejemplo, como hice en colaboración de Servicios sociales y las AMPAs de unas escuelas del Baix Empordà. Crear demanda. Con la demanda vendrá la necesidad de regular, de establecer dentro de lo público (no solo lo privado como algo elitista) este profesional que es el arteterapeuta. De lo pequeño a lo grande. Paso a paso. Y publicar, publicar, explicar hasta la saciedad. Mostrarnos. Visibilizar y naturalizar nuestra profesión hasta que sea algo ya normal. Naturalizar es una palabra para mí que hace eco en mi mente y tiene mucha fuerza. Hay mucho por hacer y animo a todas las terapias expresivas colaboren para una sociedad, más bella, más sana, más abierta a aceptar lo extraño como propio, me viene a la mente 
el transito y situación de los refugiados y la maternidad e infancia que puedan tener y como esto generará traumas, entre otras repercusiones. Charles Darwin dijo "no es la raza más fuerte la que sobrevive, si no la que mejor se adapta al cambio". Como arteterapeutas quizás podamos ayudar a transitar cambios a muchas personas empezando por el tránsito de ayudar a la madre a desapegarse del cordón umbilical que le une a su bebé y ayudarla a apegarse sanamente a otro tipo de vinculo que aunque invisible, es más fuerte que cualquiera; el amor.

\section{Referencias bibliográficas}

Bertín, M.A. (2005). La educación prenatal natural. Madrid. Editorial Mandala.

Blanco, M. (2012). Autoetnografía: una forma narrativa de generación de conocimientos. andamios vol.9 no.19 México (may./ago. 2012)

Cánovas S.G. (2010). El oficio de ser madre. La construcción de la maternidad. Barcelona. Editorial Paidós.

Federico, G.F. (2003). Música prenatal. Buenos Aires. Editorial Kier.

Federico, G.F. (2007). El embarazo musical. Comunicación, estimulación y vínculo prenatal a través de la música. Buenos Aires. Editorial Kier.

Gibson, J. J. (1986). The ecological approach to visual perception. Hillsdale, NJ: Lawrence Erlbaum. (Trabajo original publicado en 1979).

Gutman, L. (2008). La maternidad y el encuentro con la propia sombra: crisis vital y revolución emocional. Barcelona. Editorial Nuevo Extremo, S.A.

Haraway, D.J.(1995) “Ciencia, cyborgs y mujeres. La reinvención de la naturaleza” Madrid, Cátedra.

Odent, M. (1984). Nacimiento Renacido. NY. Panteón

Santiago, C. (2000). Vitaminas de Luz, el lado invisible de la gestación. Venezuela. G.S.C Ediciones.

Schutz, P.S. (1990). A mi hija con amor, sobre las cosas importantes de la vida. Buenos Aires. Ed. Vergara. 1990

Verny, T. \& Weintraub, P. (1992). El vínculo afectivo con el niño que va a nacer. Barcelona. Ed. Urano.

Winnicott; D.W. (2005) Realidad y juego. Barcelona. Editorial Gedisa.

Wirth, F. (2001). Prenatal Parenting: The Complete Psychological and Spiritual Guide to Loving Your Unborn Child. UK: Harper Collins.

\section{Páginas web}

A.N.E.P., Asociación Nacional de Educación Prenatal, recuperado el 26/06/2016 de http://anepeducacion.blogspot.com.es/

Esther Santiago Hernández, psicóloga, musicoterapeuta, magisterio musical y madre, dirige grupos de mujeres y los portales webs recuperado el 26/06/2016 de http://www.lavozdelamaternidad.com/ y de http://www.entremujeres.es

Fundación Madrina, web recuperado el 26/06/2016, http://madrina.org

Marie Laurel-Potel, psicofonista desde 1984, se ha centrado en el desarrollo del Canto Prenatal, web recuperado el 26/06/2016, http://envie-de-chanter.com/ 